\title{
Transitioning to $100 \%$ Tobacco-Free: Perspectives from a Jesuit University
}

\author{
Susan Bartos, PhD, RN, CCRN \\ Karen Donoghue, MA \\ Patrick Kelley, MD, DrPH \\ Fairfield University
}

\begin{abstract}
Aim: The purpose of this study is to examine the current social climate around tobacco at a Jesuit University and begin implementation procedures to transition the campus to a $100 \%$ tobacco free environment in a manner consistent with Jesuit and personal values.

Background: Smoke-free campus policies are shown to be successful in reducing the amount of smoking and exposure to second-hand smoke. A comprehensive policy which includes traditional cigarettes, e-cigarettes, smokeless products, and hookah is recommended to eliminate the cultural acceptance of all tobacco products.

Methods: A web-based survey was conducted following feedback from student led focus groups.

Results: The majority of students (71\%) agreed or strongly agreed with a transition to a tobacco-free policy with only $18 \%$ of the participants reporting negative feelings towards the policy change. Slightly more than half of the sample (53\%) reported having a knowledge deficit related to available smoking cessation resources.

Conclusions: There is an important balance between individual freedoms and upholding core Jesuit values in caring for the whole person. When implementing a new tobacco-policy, the current social climate, educational and cessation resources, and policy enforcement should be considered.
\end{abstract}

Submitted 23 February 2017; accepted 29 March 2017

Keywords: college, tobacco-free, universities, Jesuit

Smoking and tobacco use are the leading contributing factors to the most common causes of death in the United States (Centers for Disease Control \& Prevention [CDC], 2016). Heart disease, cancer, and respiratory illnesses top the list as the most prevalent causes of mortality and can all be attributed to the detrimental effects of smoking (CDC, 2016). Tobacco usage remains a concern among college students. According to the Population Assessment of Tobacco and Health (PATH) Study, nearly 38\% of young adults, aged 18 to 24 years, reported using a tobacco product between the years of 2013 and 2014 (Kasza et al., 2017). Reducing tobacco-related diseases, illnesses and disabilities are objectives of Healthy People 2020. In one year, cost-savings related to reducing tobacco-related diseases have been estimated to exceed $\$ 300$ billion and the 500,000 lives that may be saved through the reduction of tobacco use is invaluable (U.S. Department of Health and Human Services, 2017).

In the United States, there are nearly 20 million students currently enrolled in a collegiate program (National Center for Education Statistics, 2016). In conjunction with the American College Health Association (ACHA, 2011) and the Centers for Disease Control and Prevention (CDC, 2016), a position statement endorsing a $100 \%$ indoor and outdoor tobacco-free collegiate environment has been published. This position statement includes guidelines to developing a tobacco policy which incorporates prevention and cessation efforts, developing a tobacco-free task force to address campus needs and concerns, and promote educational activities focused on addressing the risks of all forms of tobacco including e-cigarettes (ACHA, 2011). In addition to the ACHA, the American Association of Colleges of Nursing (AACN, 2016) has endorsed a resolution which calls for tobacco-free Schools of Nursing.

This study is an examination is of the current policy and social climate at Fairfield University (2017), one of 28 Jesuit Universities in the United States. The campus of approximately 10,000 students of both undergraduates and graduates is fully accredited by the New England Association of Schools and Colleges. Currently, a tobacco policy which prohibits the use of tobacco products within 30 feet of any campus entryway is in effect. Previously conducted studies have demonstrated that these restrictions may be unsuccessful in decreasing second-hand smoke exposure 
(Lupton \& Townsend, 2015) and a more detailed and regulated policy is needed.

Recently, polls were conducted at Fairfield University to measure student perspectives on a 100\% tobacco-free environment and the majority of students (70\%) support the implementation of such a policy. In the fall of 2015, the University conducted the American College Health Association National College Health Assessment and discovered $16.2 \%$ of surveyed students reported using cigarettes. This is similar to the national average of $15.2 \%$ among adults aged 18 and older (Benjamin, et al., 2017).

Using information obtained through this survey, an interdisciplinary task-force was created to develop, implement, and enforce a tobacco-free policy that upheld University standards and the general principles of a Jesuit education such as Cura Personalis, the care of the whole person. The purpose of this study is to examine the current social climate around tobacco at a Jesuit University and begin implementation procedures to transition the campus to a $100 \%$ tobacco free environment in a manner consistent with Jesuit and personal values.

\section{Cura Personalis}

Founded by the society of Jesus in 1942, Fairfield University embraces the identity and mission of the Catholic and Jesuit mission. The University's institutional mission promotes a dynamic education which integrates a strong foundation in liberal arts and sciences. This core curriculum prepares the students to learn and lead in a community while being insightful and promoting social justice. As a part of the Catholic and Jesuit mission, Fairfield University also embraces the ideals of Cura Personalis, by placing strong emphasis on caring for the mind, body and spirit of all individuals who choose to live and work at the institution. Fostering an environment focused on health and wellness that allows each individual to thrive and perform to the highest degree is in line with both the Jesuit mission and the implementation of a 100\% tobacco-free environment.

\section{Literature Review}

Scholarly, peer-reviewed literature focused on transitioning college campuses to smoke and tobacco-free environments dates back to the early 2000's (Halperin \& Rigotti, 2003; Rigotti, Regan, Moran \& Wechsler, 2003; Bower \& Enzler, 2005). As of January 2017, there are nearly 1800 Colleges and Universities that define themselves as smoke-free and nearly 1500 of these institutions are 100\% tobacco-free (American NonSmoker's Rights Foundation, 2017). Smokefree campuses have been shown to be successful in reducing the amount of smoking and exposure to second-hand smoke (Lupton \& Townsend, 2015).

It is important to understand the population that a tobacco-free policy will effect. Social determinant variables such as gender, race and political affiliation may influence the acceptability of a new tobacco policy. While some studies have demonstrated a higher amount of female tobacco users (Mamudu, Verranki, Kioko, Boghozian, \& Littleton, 2015) and no difference in race (Hall, Williams, \& Hunt, 2015), the majority of tobacco users that are college-aged (18 - 24 years) are males, racial minorities, sexual minorities and those living at a lower socioeconomic status (Kasza et al., 2017).

Transparency is also important throughout the transition to a tobacco-free environment and it is recommended that campus health officials openly communicate measured levels of tobacco use, information regarding noncigarette products, and provide ample and evidence-based education (Braverman, Hoogesteger, Johnson, Aaro, 2017). A comprehensive policy which includes traditional cigarettes, e-cigarettes, smokeless products, and hookah is recommended to facilitate the cultural acceptance of all tobacco products (Reindl, Glassman, Price, Dake, \& Yingling, 2014). This policy should be supported and promoted by the University President and should be evaluated over time (Reindl, et al., 2014).

The proposal to transition the Fairfield campus to one that was tobacco-free was originally suggested by a senior nursing student. Following the student government constitution, this proposal prompted the Fairfield University Student Association (FUSA) Senate to pass a resolution to begin the process of investigating a tobacco-free campus. Prior to this resolution, the University had seen a decline in student usage of tobacco products throughout campus. As similar to many other institutions, tobacco products were often utilized when students were socializing or studying late at night. In general, the University has seen a significant decline in any policy violation related to the University 
smoking policy. It is in the interest of the University to create an environment of wellness and for students, faculty, and staff. Establishing a clean air environment supports this movement. Implementation of a tobacco-free campus is also supportive of creating an environment of health and wellness at Fairfield University. A tobacco-free campus supports the Healthy Campus 2020 goals put forth by the American College Health Association of reducing cigarette, hookah, and smokeless tobacco use among college students (ACHA, 2016). This student driven initiative, combined with the overall decline in tobacco products on campus, and establishment of a comprehensive environment of wellness, is what prompted the University to take a closer look at its current tobacco policy and determine the suitability of movement towards a total tobacco ban.

\section{Methods}

To begin the process of transitioning to a tobacco-free campus, student government representatives started to assess the attitudes among their peers in regards to smoking and transitioning to a stricter tobacco policy. A student committee was formed to survey their peers and research best practices from other institutions that had experienced similar transitions. Over the course of 16 months, the tobacco free student sub-committee organized two student body surveys and held two open forum dialogues for the student body.

An internet-based survey was the distributed by the student government to gain a deeper understanding of the current attitudes and social climate on the campus prior to the implementation of a tobacco-free campus. Descriptive statistics were used for the numerical data and student comments were evaluated qualitatively. The survey was developed by students that represented the student government and aimed to test the current social climate on campus. The survey was distributed via Survey Monkey and available to traditional undergraduate students.

\section{Results}

A total of 172 students participated in the survey. The breakdown by graduating class can be seen in Table 1 . While this is a small representation of the student body, 122 students (71\%) agreed or strongly agreed with a transition to a tobacco-free policy with only $18 \%(n=31)$ of the participants reporting negative feelings towards the policy change. The majority of students that participated in the poll $(53 \%, n=92)$ reported being unaware of smoking cessation programs available through counseling services on campus. When asked if a tobacco-free policy would have had an impact on the decision to attend the University, an overwhelming majority (72\%) disagreed.

Table 1.

Breakdown of Students by Class Participating in the Survey

\begin{tabular}{|c|c|}
\hline Class Year & Number of Participants (\%) \\
\hline 2017 (Senior) & $40(23 \%)$ \\
\hline 2018 (Junior) & $37(22 \%)$ \\
\hline 2019 (Sophomore) & $53(31 \%)$ \\
\hline 2020 (Freshman) & $42(24 \%)$ \\
\hline Total & $172(100 \%)$ \\
\hline
\end{tabular}

When asked to comment on the policy change, students offered a wide range of commentaries. One student remarked about implementing designated smoking areas, "Smoking on campus is no longer a personal choice if other students are subject to second-hand smoking. Designated areas should be put in place for a smoke-free campus to reduce this." While some comments are supportive of a tobacco-free campus, "I think it promotes a healthy lifestyle. No harm done there," there were comments that viewed a tobacco-free campus unfavorably. Students stated, “...Do not agree with the step to make this campus smoke free. As we are college students we need to become adults to make decisions for ourselves and not be sheltered any longer." 


\section{Discussion}

Fairfield University, a Jesuit University in New England, recognized a need for establishing a tobacco-free policy to endorse a healthy academic environment. Balancing the foundational concepts of Cura Personalis (caring for the whole person: body, mind and spirit), while promoting individual human rights and freedoms, are ongoing concerns for Universities of all foundational backgrounds. It is vital that the University provide ample evidence and education focused on smoking cessation for faculty, staff, and students. Undergraduate students are attending college during years of continued brain development and should not be exposed to the detrimental effects of second hand smoke. In adhering to the Jesuit foundations, a tobacco restriction on campus would balance the care of the body and mind. It is crucial that health officials who are promoting a healthy academic environment clearly delineate the relationship between freedoms: freedoms to clean air through the elimination of exposure to second-hand smoke and freedoms for individual choices (Wilson, Goldstein \& Pennington, 2015).

\section{Promoting an Environment of Wellness}

In addition to the tobacco-free campus initiative, campus health officials and student representatives also engaged in a larger conversation around health habits. This holistic approach considered the physical, mental, and spiritual wellbeing of all students, faculty, and staff. According to a press release by the University, a significant renovation project to the recreational complex on campus was unveiled and welcomed new staff members in Counseling and Campus Ministry to support mental health services. These strategic additions to the University solidified health and wellness as a priority (Fairfield University, 2016).

Both students and faculty have increased their usage of recreation services. The recreation complex has seen a $20 \%$ increase in daily users from 2015 to 2016. Faculty and staff memberships in the complex have also increased. In 2015, there were 671 faculty and staff memberships. To date, there are 719 faculty memberships, demonstrating a $7 \%$ increase.

Students have also shown increasing interest in focusing on bettering their mental health as evidenced by a steady and consistent increase in the use of campus counseling services. In the academic year of 2013-2014, 510 students attended 2,146 counseling sessions. These figures increased to 579 and 3,154 during the academic year of 2015-2016. Sunday mass participation had remained the same but students were actively involved in conversations within their residence halls concerning their spiritual journey and purpose.

\section{Establishing an Interdisciplinary Wellness Committee}

An interdisciplinary Wellness Committee composed of faculty from the nursing, health studies, and biology/ nutrition departments, University recreation, Student Health Services, Human Resources, and Counseling services was formed as a way of communicating ideas and inter-campus collaboration. From the Wellness Committee, a smaller subcommittee emerged, which included the Dean of Students, Department of Public Safety, Department of Facilities, in addition to campus health officials. This subcommittee was dedicated to writing, implementing, and supporting the new tobacco-free policy. Such task-forces have been supported in the literature (Braverman, et al., 2017) and help to ensure the ideals of various campus departments are being considered throughout the process of policy development.

\section{Updating the Current Tobacco Policy}

Fairfield University's tobacco policy states, “Students who wish to smoke must go outside and are required to be a reasonable distance (30 feet) away from the building to prevent smoke from entering the hall or rooms through open windows or doors." As it was reflected through student polls, this policy was not sufficient in preventing second hand smoke exposure nor did this policy support the direction of an environment of health and wellness. The tobaccofree subcommittee proposed moving the University towards a tobacco-free environment and amending the policy to create a tobacco-free campus after conducting a survey which studied current smoking and tobacco habits. 
The majority of students who participated in this survey would not have let a tobacco-free policy influence their decision to attend the University. Previous studies have shown this to be consistent in the literature (Miller, Yu, Lee, Ranney, Simons, \& Goldstein, 2015). University officials may be hesitant to implement and enforce a tobacco-free policy due to the possibility of a decline in enrollment or increase in attrition. However, changing the culture and non-acceptance of tobacco may appeal to a population that is focused on health and wellness and may give those attempting to quit using tobacco products access to evidence-based resources.

Braverman and colleagues (2017) stress the importance of strong educational and smoking cessation resources. As the majority of students that had participated in this survey (54\%) were unaware of smoking cessation programs, it is important for this University to ensure resources are readily available. Health campus officials including 2 registered nurses (RNs) have met with and secured cessation resources through a program affiliated with a local hospital. Representatives on the smaller tobacco task-force from the Human Resources department have also confirmed the insurance coverage for cessation programs for those faculty and staff participating in University insurance plans. Availability of cessation programs to both students and faculty/staff are best practice recommendations for implementing a tobacco policy (Plaspohl, Parrollo, Vogel, Terrders, \& Epstein, 2012).

One of the largest challenges that the University faces is how to fairly enforce the new tobacco policy. Students that participated in this survey commented on the lack of current enforcement which prohibits smoking within 30 feet of any campus entrance, “...the 30 feet rule isn’t always obeyed.” Enforcement issues, including lack of a point person or faculty/staff support have been identified as additional barriers to implementing a tobacco-free policy (Reindl et a 1., 2014). Throughout the implementation of the new tobacco policy, it will be imperative for campus health officials and representative student peers to target policy education with those who are noncompliant with the current policy, rewarding those who adhere to the new policy and provide positive reinforcement and cessation resources to those in need (Russette, Harris, Schuldberg, \& Green, 2014).

\section{CONCLUSIONS}

The implementation of a tobacco-free campus is widely supported in academic literature and supports the national goals of Healthy Campus 2020, Healthy People 2020, and recommendations from the American Association of Colleges of Nursing. After conducting a survey to describe current tobacco habits, it was decided that a move towards a tobacco-free campus was warranted. The current tobacco policy at Fairfield University has been revised to include designated smoking areas with a plan to transition to a 100\% tobacco-free environment over the next 16 months. Understanding the current social climate while upholding core values of the institution, such as Cura Personalis, is vital to the success of a tobacco-free policy. Implementing such a policy solidifies an organization's commitment to creating a living and working environment that is focused on the health and wellness of its constituents. 


\section{REFERENCES}

American Academy of Colleges of Nursing (2016). AACN members endorse resolution calling for smoke and tobacco-free schools of nursing. Retrieved from: http://www.aacn.nche.edu/news/articles/2016/smoke-tobacco-free

American College Health Association (2011). Position statement on tobacco on college and university campuses in $A C H A$ Guidelines. Retrieved from: http://www.acha.org/documents/resources/guidelines/ACHA_Position_Statement_on_ Tobacco_Nov2011.pdf

American College Health Association (2016). Student objectives in Healthy Campus 2020. Retrieved from: https://www.acha. org/HealthyCampus/Objectives/Student_Objectives/HealthyCampus/Student_Objectives.aspx?hkey=a9f191de243b-41c6-b913-c012961ecab9.

Americans for Non-Smokers' Rights (2017). College and Universities. Retrieved from: http://no-smoke.org/goingsmokefree.php?id=447

Benjamin, E.J., Blaha, M.J., Chiuve, S.E., Cushman, M., Das, S.R., Deo, S.R., .. Muntner, P.(2017). Heart Disease and Stroke Statistics - 2017 Update. Circulation, 2017(135). https://doi.org/10.1161/CIR.0000000000000485

Bower, G.G., \& Enzler, D. (2005). Protecting students and faculty from environmental tobacco smoke: An assessment and rationale for college policies prohibiting smoking in public area and student residencies. Health Education, 105(4), 259272. https://doi.org/10.1108/09654280510602480

Braverman, M.T., Hoogesteger, L.A., Johnson, J.A., \& Aaro, L.E. (2017). Supportive of a smoke-free campus but opposed to a $100 \%$ tobacco-free campus: Identification of predictors among university students, faculty, and staff. Preventative Medicine,94(2017), 20-26. https://doi.org/10.1016/j.ypmed.2016.10.021

Centers for Disease Control (CDC), Office on Smoking and Health (2016). Tobacco-Related Mortality in Smoking \& Tobacco Use. Retrieved from: https://www.cdc.gov/tobacco/data_statistics/fact_sheets/health_effects/tobacco_related_ mortality/

Fairfield University. (2016). Grand Opening of Newly Renovated RecPlex at Fairfield University- Sept 2. Retrieved from: https://www.fairfield.edu/lassochannel/press/pr_index/index.lasso?id=4514

Fairfield University (2017). Tobacco-Free Campus. Retrieved from: https://www.fairfield.eduundergraduate/student-life-andservices/health-and-wellness/tobacco-free/

Hall, M.E., Williams Jr., R.D., \& Hunt, B. (2015). Assessment of attitudes regarding tobacco-free campus policy and secondhand smoke exposure among college students, faculty, and staff. American Journal of Health Education, 46, 48-57. https://doi.org/10.1080/19325037.2014.945671

Halperin, A.C., \& Rigotti, N.A. (2003). US public universities' compliance with recommended tobacco-control policies. Journal of American College Health, 51(5), 181-188. https://doi.org/10.1080/07448480309596349

Kasza, K.A., Ambrose, B.K., Conway, K.P., Borek, N., Taylor, K., Goniewicz, M.L. ... Hyland, A.J. (2017). Tobacco-product use by adults and youths in the United States in 2013-2014. The New England Journal of Medicine, 376(4), 342-353. https://doi.org/10.1056/NEJMsa1607538

Lupton \& Townsend (2015). A systematic review and meta-analysis of the acceptability and effectiveness of university smoke free polices. Journal of American College Health, 63(4), 238-247. https://doi.org/10.1080/07448481.2015.1015029

Mamudu, H.M., Verranki, S.P., Kioko, D.M., Boghozian, R.K., \& Littleton, M. (2016). Exploring support for 100\% college tobacco-free policies and tobacco-free campuses among college tobacco users. Journal of Public Health Management Practice, 22(1), 29-39. https:// doi.org/10.1097/PHH.0000000000000262

Miller, K.D., Yu, D., Lee, J.G., Ranney, L.M., Simons, D.J., \& Goldstein, A.O. (2015). Impact of the adoption of tobacco-free campus policies on student enrollment at colleges and universities, North Carolina 2001-2010. Journal of American College Health, 63(4), 230-236. https://doi.org/10.1080/07448481.2015.1015023

National Center for Education Statistics. (n.d.) Fast Facts: Back to School Statistics. Retrieved from: https://nces.ed.gov/fastfacts/display.asp?id=372 
Plaspohl, S.S., Parrillo, A.V., Vogel, R., Tedders, S., \& Epstein, A. (2012). An assessment of America's tobacco-free colleges and universities. Journal of American CollegeHealth, 60(2), 162-167. https://doi.org/10.1080/07448481.2011.580030

Reindl, D., Glassman, T., Price, J., Dake, J., \& Yingling, F. (2014). Perception of college and university presidents regarding tobacco-free campus policies. Journal of American College Health, 62(3), 193-202. https://doi.org/10.1080/07448481.2013.877019

Rigotti, N., Regan, S., Moran, S., \& Wechsler, H. (2003). Students' opinion of tobacco control polices recommended for US colleges: A national survey. Tobacco Control, 12(3), 251-246. https://doi.org/10.1136/tc.12.3.251

Russette, H.C., Harris, K.J., Schuldberg, D., \& Green, L. (2014). Policy compliance of smokers on a tobacco-free university campus. Journal of American College Health, 62(2), 110-116. https://doi.org/10.1080/07448481.2013.854247

United States Census Bureau (2016). School Enrollment in the United States. Retrieved from: https://www.census.gov/ newsroom/press-releases/2016/cb16-tps142.html.

U.S. Department of Health and Human Services. (2017). Tobacco Use in Healthy People 2020.Retrieved from: https://www.healthypeople.gov/2020/topics-objectives/topic/tobaco-use

Wilson, K.M., Goldstein, C., \& Pennington, K. (2015). Attitudes and practices about tobacco smoking at a Jesuit University: Cura personalis or individual rights? Jesuit Higher Education: A Journal, 4(2), 28-36.

Author correspondence may be addressed to:

Susan Bartos, PhD, RN, CCRN

Assistant Professor

Fairfield University Egan School of Nursing \& Health Studies

1073 North Benson Road

Fairfield, CT 06824

sbartos@fairfield.edu 